\title{
Accidental haemorrhage in third trimester: maternal and fetal outcome
}

\author{
Niranjan N. Chavan*, Vibhusha Rohidas, Hanumant Waikule
}

Department of Obstetrics and Gynecology, LTMMC and GH, Mumbai, Maharashtra, India

Received: 11 February 2019

Accepted: 07 March 2019

\section{*Correspondence:}

Dr. Niranjan Chavan,

E-mail: nnchavan22@gmail.com

Copyright: (C) the author(s), publisher and licensee Medip Academy. This is an open-access article distributed under the terms of the Creative Commons Attribution Non-Commercial License, which permits unrestricted non-commercial use, distribution, and reproduction in any medium, provided the original work is properly cited.

\section{ABSTRACT}

Background: Abruptio placenta or accidental haemorrhage is one of the obstetrical emergencies and is truly accidental with few warning signs. Present study is planned to study the maternal and fetal outcome in patients of abruption placenta in a tertiary care referral hospital in a rural set up which is helpful to plan management strategies and to decrease mortality and morbidity.

Methods: A prospective observational study was conducted at Department of Obstetrics and Gynaecology at tertiary care centre during September 2015 to August 2019. A total of 270 cases of abruptio placenta coming to the labor ward and delivered were included in the study. The information collected regarding maternal and fetal parameters were recorded in a master chart in Microsoft Excel 2010 and analyzed using the statistical package for the social sciences software (SPSS) version 20.0.

Results: In the present study there were a total of 29887 deliveries with 270 cases of abruptio placenta, incidence being $0.9 \%$. Bleeding per vagina is the most common presentation $(85.6 \%)$ followed by pain abdomen $(70.7 \%)$. Common risk factors for accidental hemorrhage were: Pre-eclampsia (39.6\%) and anaemia (32.2\%). Rate of cesarean section was $40.7 \%$ (n-110) while rate of forceps delivery was $4.8 \%$ (n-13). Associated maternal complications include: post-partum hemorrhage (18.9\%), DIC (10\%), acute renal failure (4.1\%) and puerperal sepsis (1.9\%) while maternal mortality rate was $1.9 \%$. Low birth weight $(<2.5 \mathrm{~kg})$ was observed in $74.8 \%$ cases while still birth and neonatal mortality rate was $35.2 \%$ and $12.6 \%$ respectively.

Conclusions: Abruptio placenta or accidental hemorrhage is major risk factor for maternal and perinatal morbidity and mortality, thus efforts should be taken to reduce risk factor for abruptio placenta. Strengthening of antenatal care, anticipation and evaluation of associated high-risk factor and prompt management of complication can improve maternal and perinatal outcome in these cases. Abruptio placenta should be managed in centers where there is advanced maternal and neonatal health care facilities are available.

Keywords: Accidental Haemorrhage, Fetal outcome, Maternal Mortality, Maternal outcome, Pre-eclampsia

\section{INTRODUCTION}

Abruptio placenta or accidental haemorrhage is one of the obstetrical emergencies and is truly accidental with few warning signs. In developed countries the incidence is $1 \%$ of deliveries, whereas in developing countries it is around $2-8 \% .^{1-3}$ In many countries the rate of placental abruption has been increasing, perhaps due to advancing maternal age and increasing caesarean section rates. ${ }^{4-7}$ It is one of the significant causes of maternal and perinatal mortality and morbidity. The incidence of maternal mortality is around $1 \%$, whereas perinatal mortality is much higher accounting for $66 \%$ of deliveries. ${ }^{4-8}$ The maternal effect of abruptio placenta depends primarily on its severity, whereas the fetal effects are determined by both severity and gestational age at which it occurs. The 
etiology of abruptio placenta is obscure. However, thereare many risk factors associated with the condition like hypertensive disorders of pregnancy, polyhydramnios, intrauterine growth restriction, advanced maternal age, maternal trauma, cigarette smoking, alcohol consumption, cocaine abuse, short umbilical cord, premature rupture of membranes, grand multiparityetc. ${ }^{9-12}$

The major maternal complications of abruption placenta are hemorrhagic shock, disseminated intravascular coagulation, acute renal failure, postpartum haemorrhage and maternal death. ${ }^{11,13}$ The poor perinatal outcome is due to low birth weight, prematurity and still birth. ${ }^{14,15}$ With the better availability of blood and blood products and coagulation factors, the management of shock and DIC has decreased the maternal and perinatal morbidity and mortality over last few decades. There has been increase in the use of caesarean delivery over recent years in abruptio placentae which have resulted in a better obstetric outcome. Present study is planned to study the maternal and fetal outcome in patients of abruption placenta in a tertiary care referral hospital in a rural set up which is helpful to plan management strategies and to decrease mortality and morbidity.

\section{METHODS}

A prospective observational study (September 2015 to August 2019) was conducted at Department of Obstetrics and Gynaecology at tertiary care centre. A total of 270 cases of abruptio placenta (after 28 weeks of gestation) coming to the labour ward and delivered were included in the study.

\section{Exclusion criteria}

- Cases coming before 28 weeks and having other causes of 3rd trimester bleeding.

Following maternal and fetal parameters in cases of accidental haemorrhage were evaluated: Risk factor for abruptio placenta, grade of abruptio placenta, mode of delivery, maternal complications (PPH, DIC, Acute renal failure, Puerperal sepsis, mortality), baby weight, APGAR score and perinatal outcome (still birth, live birth, neonatal death).

The information collected regarding all the selected cases was recorded in a Master Chart in Microsoft Excel 2010 and analysed using the statistical package for the social sciences software (SPSS) version 20.0.

\section{RESULTS}

In the present study there were a total of 29887 deliveries with 270 cases of abruptio placenta, incidence being $0.9 \%$. Mean age of the study subjects was 28.32 years with $41.5 \%$ (n-112) were in the age group of 26-30 years. Out of total 270 cases, $32.2 \%$ females were primi-para (n-87) while half of them (n-51.9\%; n-140) presented at gestational age between 33-37 weeks. Common risk factors for accidental haemorrhage were: Pre-eclampsia (39.6\%), anaemia (32.2\%), Polyhydramnios (7\%), multiple pregnancy and Trauma (1.5\% each). No risk factor was identified in $18.1 \%$ cases (Table 1).

Table 1: Distribution of patients as per risk factors.

\begin{tabular}{|l|l|l|}
\hline Risk factors & N & $\%$ \\
\hline Pre-eclampsia & 107 & 39.6 \\
\hline Anaemia & 87 & 32.2 \\
\hline Polyhydramnios & 19 & 7.0 \\
\hline Multiple pregnancy & 4 & 1.5 \\
\hline Trauma & 4 & 1.5 \\
\hline Unknown & 49 & 18.1 \\
\hline Total & 270 & 100.0 \\
\hline
\end{tabular}

Most of the women presented with grade $1(36.3 \%)$ and grade $2(34.1 \%)$ abruption while grade 3 abruption was seen in $27.8 \%$ cases (Figure 1).

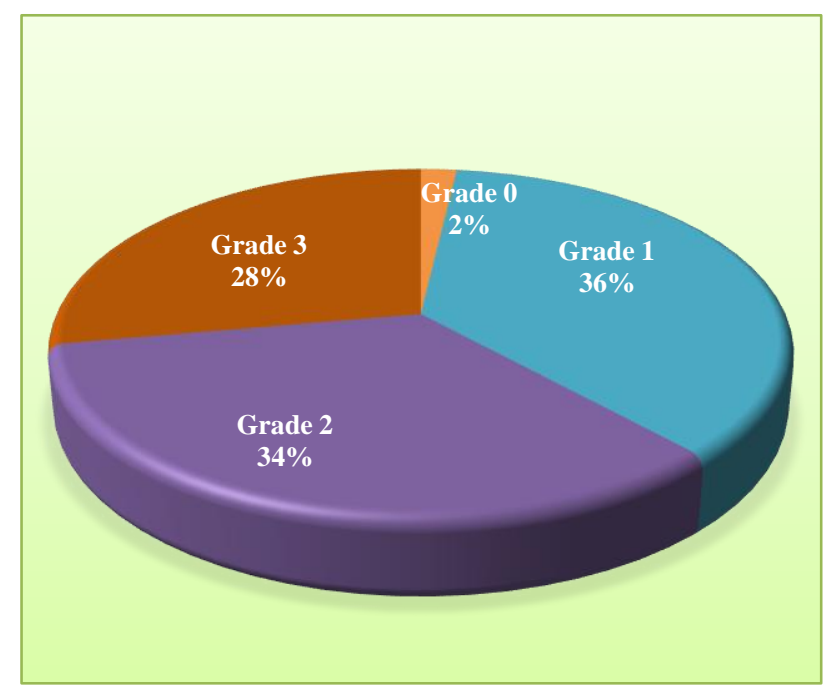

Figure 1: Distribution of cases as per grade of abruption.

Bleeding per vagina is the most common presentation $(85.6 \%)$ followed by pain abdomen $(70.7 \%)$, absent fetal heart sounds $(35.9 \%)$, fetal distress $(32.6 \%)$, uterine contractions (23\%) and hypotension (10\%) (Table 2).

Table 2: Distribution of patients as per presenting features.

\begin{tabular}{|l|l|l|}
\hline Presenting Features & N & $\%$ \\
\hline Bleeding PV & 231 & 85.6 \\
\hline Pain in abdomen & 191 & 70.7 \\
\hline Fetal distress & 88 & 32.6 \\
\hline Abnormal uterine contractions & 62 & 23.0 \\
\hline Absent FHS & 97 & 35.9 \\
\hline Hypotension & 27 & 10.0 \\
\hline
\end{tabular}


Rate of cesarean section was $40.7 \%$ (n-110) while rate of forceps delivery was $4.8 \%(n-13)$. Associated maternal complications include: post-partum haemorrhage $(18.9 \%)$, DIC $(10 \%)$, acute renal failure $(4.1 \%)$ and puerperal sepsis $(1.9 \%)$ while maternal mortality rate was $1.9 \%$ (Table 3 ).

Table 3: Distribution of patients as per maternal complications.

\begin{tabular}{|l|l|l|}
\hline Maternal complications & N & $\%$ \\
\hline PPH & 51 & 18.9 \\
\hline DIC & 27 & 10.0 \\
\hline ARF & 11 & 4.1 \\
\hline Puerperal sepsis & 5 & 1.9 \\
\hline Mortality & 5 & 1.9 \\
\hline
\end{tabular}

Low birth weight $(<2.5 \mathrm{Kg})$ was observed in $74.8 \%$ cases while still birth and neonatal mortality rate was $35.2 \%$ and $12.6 \%$ respectively (Table 4 ).

Table 4: Distribution of patients as per fetal complications.

\begin{tabular}{|l|l|l|}
\hline Fetal complications & N & $\%$ \\
\hline LBW & 202 & 74.8 \\
\hline Still Births & 95 & 35.2 \\
\hline Neonatal Deaths & 34 & 12.6 \\
\hline
\end{tabular}

\section{DISCUSSION}

In the present study there were a total of 29887 deliveries. Of these there were 270 cases of abruptio placenta, incidence being $0.9 \%$. Similar incidence was found by Vijayasree et al. (2.5\%), Singh AG et al. (1\%), Jerry Coleman et al. (1.4\%), T. Lakshmi et al. (0.3\%), Sumangala Devi et al. (0.9\%). ${ }^{15-19}$ Studies conducted by IramSarwar et al showed that most of the women with abruptio placenta presented with gestational age between 28-33 weeks. The study conducted by Singh AG et al., Vrunda Choudhary et al showed that more than $50 \%$ were between 33.1 to 37 weeks of gestation at the time of presentation. ${ }^{16,20,21}$ Present study showed similar higher incidence $(51.9 \%)$ between 33 to 37 weeks of gestation at the time of presentation. Common risk factors for accidental hemorrhage in present study were Preeclampsia $(39.6 \%)$, anaemia $(32.2 \%)$, Polyhydramnios (7\%), multiple pregnancy and Trauma (1.5\% each). No risk factor was identified in $18.1 \%$ cases. Similarly, in studies conducted by Singh AG et al, Saira Dars et al. and Vrunda Choudhary et al. the incidence of pre-eclampsia as $56.86 \%, 59.13 \%$ and $45.15 \%$ respectively. In study conducted by Singh AG et al, Saira Dars et al. the incidence of anemia as risk factor was $31.37 \%$ and $38.26 \%$ respectively which is similar to the present study. ${ }^{16,21,22}$

Most of the women presented with grade $1(36.3 \%)$ and grade $2(34.1 \%)$ abruption while grade 3 abruption was seen in $27.8 \%$ cases. In a study conducted by Sumangala
Devi et al., similar incidences were found showing Grade 1 as $37.5 \%$, Grade 2 as $37.5 \%$ and Grade 3 as $28.5 \%$. In study conducted by Jerry Coleman et al. incidence were found showing Grade 0 was $0 \%$ Grade1 was $31 \%$, Grade 2 was $11 \%$ and Grade 3 was $58 \% .^{17,19}$ Bleeding per vagina is the most common presentation (85.6\%) followed by pain abdomen $(70.7 \%)$, absent fetal heart sounds (35.9\%), fetal distress $(32.6 \%)$, uterine contractions $(23 \%)$ and hypotension $(10 \%)$. Bleeding per vaginum is most common presenting complaint in all studies, Vijayasree et al. (80\%), Iram Sarwar et al. (96.2\%), Jerry Coleman et al. (83\%) and Soma Mukharji et al. ${ }^{15,17,20,23}(90.6 \%)$ which is similar to present study. Pain abdomen/Uterine tenderness as the next frequent presenting complaint was observed in Jerry Coleman et al. (79\%) and Soma Mukharji et al. (71.9\%) which is similar to present study. ${ }^{17,23}$ Rate of cesarean section was $40.7 \%$ (n-110) in present study. Similar results were found in studies conducted by Aesha Patel et al (43\%), Vrunda Choudhary et al. $(45.97 \%)$ and Saira Darset al. $(35.65 \%)$. The caesarean rates in other studies: Iram Sarwar et al. (30.2\%), Singh AG et al (21.57\%) and T. Lakshmi Suseela et al $(30.9 \%)$ were also similar to present study. However, in study conducted by Jerry Coleman et al. (83\%) and Sumangala Devi et al. (57.9\%) the cesarean rates were high. ${ }^{16,17,19,20-24}$ Incidence of PPH was $18.9 \%$ in present study which is similar to study conducted by Iram Sarwar et al. (18.9\%), Jerry coleman et al. (21\%) Musarrat Jabeen et al. (14.56\%), Vrunda Choudhary et al. (22.59\%). Incidence of DIC, Acute renal failure, and puerperal sepsis in present study was $10 \%, 4.1 \%$ and $1.9 \%$ respectively. ${ }^{17,20,21,25}$ Incidence of DIC in present study (10\%) was similar to Aesha Patel et al. (9\%) and Jerry Coleman et al. (11\%), DIC in study conducted by Musarrat Jabeen et al., Vrunda Choudhary et al., Soma Mukharji et al., Sumangala Devi et al, Singh AG et al and Saira Dars et al were 16.55\%, 20.16\%, 22\%, $3.6 \%, 3.92 \%, 4.35 \%$ respectively. ${ }^{17,19,21,22,24,25}$ Acute renal failure in present study was $4 \%$ which was similar to studies conducted by Saira Dars et al. (4.35\%), Soma Mukharji et al. (7.5\%) and Aesha Patel et al. (7\%). Incidence of Puerperal sepsis in present study was $1.9 \%$ which is similar to Sumangala Devi et al. (3.2\%) and Soma Mukharji et al. (4.7\%). ${ }^{19,22,23,24}$

The Maternal mortality in present study was $1.9 \%$. Similar results were noted in all other studies. Studies conducted by Singh AG et al, Saira Dars et al, Jerry Coleman et al, MusarratJabeen et al, VrundaChoudhary et al, T. Lakshmi Suseela et al and Sumangala Devi et al found maternal mortality $1.96 \%, 2.61 \%, 2 \%$, $1.32 \%, 0 \%, 0 \%$ and $0 \%$ respectively. ${ }^{16-19,21,22,25}$ Low birth weight $(<2.5 \mathrm{Kg})$ was observed in $74.8 \%$ babies among present study. Seema bibi et al study showed that baby weight $<2.5 \mathrm{~kg}$ in $70 \%$ babies. Iramsarwar et al study showed that baby weight $<2.5 \mathrm{~kg}$ in $66.6 \%$ babies while Soma Mukharji et al observed baby weight $<2.5 \mathrm{~kg}$ in $70.6 \%$ babies. $^{20,23,26}$ In present study, perinatal mortality rate was $47.8 \%$.Similar results were noted in studies by Sumangala Devi et al. (47\%), Aeshapatel et al 
(42.8\%). ${ }^{19,24}$ However, few studies the perinatal mortality rate was high like in Iramsarwar et al (67.9\%), Singh AG et al $(68.62 \%)$ and Vrunda Choudhary et al $(58.07 \%)$. Perinatal mortality in the present study was due to high rate of dead fetus at presentation, more number of premature babies and late presentation to hospital. ${ }^{16,20,21}$

\section{CONCLUSION}

Abruptio placenta or accidental haemorrhage is major risk factor for maternal and perinatal morbidity and mortality, thus efforts should be taken to reduce risk factor for abruptio placenta. Strengthening of antenatal care, anticipation and evaluation of associated high-risk factor and prompt management of complication can improve maternal and perinatal outcome in these cases. Abruptio placenta should be managed in centers where there is advanced maternal and neonatal health care facilities are available.

\section{Funding: No funding sources}

Conflict of interest: None declared

Ethical approval: The study was approved by the Institutional Ethics Committee

\section{REFERENCES}

1. Vigid De Gracia P, Montufar RC, Smith A. Pregnancy and severe chronic severe chronic hypertension: maternal outcome. Hypertens Pregn. 2004;23(3):28593.

2. Noorani KJ, Noorani M. Prevalance of acute renal failure in patients developing abruptio placentae as a consequence of PIH. Pakistan J Obstet Gynecol. 1995;8(1):15-6.

3. Sadia Z Khan AZ, Naheed F. Fetal outcome varies with different grades of placental abruption. Ann Kind Edward Med Coll. 2003;9 (1):40-2.

4. Ananth CV, Oyelese Y, Yeo L, Pradhan A, Vintzileos AM. Placental abruption in the United States, 1979 through 2001: Temporal trends and potential determinants. AJOG. 2005;192(1):191-8.

5. Saftlas A, Olsen D, Atrash H. National trends in the incidence of abruptio placenta. ObstetGynecol 1991;78(6):1081-6.

6. Rasmussen S, Irgens LM, Bergsjo P, Dalaker K. The occurrence of placental abruption in Norway 19671991. Acta Obstet Gynecol Scand 1996;75(3):222-8.

7. Hossain N, Khan N, Sultana S and Khan N. Abruptio placenta and adverse pregnancy outcome. J Pak Med Assoc. 2010;60(6):443-6.

8. Gaufberg SV. Abruptio Placentae 2001 Available from: http://www.emedicine.com/emerg/topic12.htm.

9. Toivonen S, Heinonen S, Anttile M, Kosma VM, Saarikoski S. Reproductive risk factors, Doppler findings, and outcome of affected births in placental abruption. Am J Perinatol 2002;19(8):451-60.
10. Sheiner E, Shoham-Vardi I, Hallak M, Hadar A, Gortzak-Uzan L, Katz M. Placental abruption in term pregnancies: clinical significance and obstetric risk factors. J MaternFetal Neonatal Med. 2003;13(1):45-9.

11. Abu-Heija A, al-Chalabi H, el-Iloubani N. Abruptio placentae: risk factors and perinatal outcome. J Obstet Gynaecol Res. Apr 1998;24(2):141-4.

12. Oyelese Y, Ananth CV. Placental abruption. Obstet Gynecol. 2006;108(4):1005-16.

13. Nath CA, Ananth CV, Smulian JC, Shen-Schwarz S, Kaminsky L. New Jersey-Placental Abruption Study Investigators. Histologic evidence of inflammation and risk of placental abruption. Am J Obstet Gynecol 2007;197(3):319 e1-6.

14. Vijayashree M. A Clinical Study of Maternal and Fetal Outcome in Abruptio Placenta-Couvelaire Uterus a Preventable Obstetric Catastrophe. Sri Lanka J Obstet Gynaecol. 2016;37(3).

15. Singh AG, Ghanghoriya V and Chauhan R. Maternal and Fetal Outcome in Abruptio Placentae at NSCB Medical College Hospital, Jabalpur. EJBPS. 2015; 2(3):1446-52

16. Coleman J, Srofenyo EK, Ofori EK, Brakohiapa EK, Antwi WK. Maternal and fetal prognosis in abruptio placentae at Korle-Bu Teaching Hospital, Ghana. Af J Reproduct Health. 2014;18(4):115-22.

17. Lakshmi ST, Jyothi SJ, Rabbani P, Jhonsi C, Evaluation of risk factors for prenatal and maternal outcome in abruption of placenta. EJPMR. 2016,3(8):541-5

18. Devi S, Kumar BV, Joshi M. Feto Maternal Outcomes in Abruptio Placenta. Int J Sci Res. 2016;5(11):669-72

19. Sarwar I, Islam A. Abruptio placentae and its complications at Ayub Teaching Hospital Abbottabad. J Ayub Med Col Abbottabad. 2006;18(1).

20. Choudhary V, Somani SR, Somani S. Evaluation of Risk factors and Obstetric and Perinatal Outcome in Abruptio Placenta. Age. 2015;21(25):26-30.

21. Dars S, Sultana F, Akhtar N. Abruptio placentae: Risk factors and maternal outcomes at a tertiary care hospital. JLUMHS. 2013;12(3):198-202.

22. Mukherjee S, Bawa AK, Sharma S, Nandanwar YS, Gadam M. Retrospective study of risk factors and maternal and fetal outcome in patients with abruptio placentae. J Nat Sci, Biol, Med. 2014;5(2):425-8.

23. Aesha Patel. Fetomaternal outcome in cases of abruptio placenta. Int J Advan Case Report. 2016;3(1):56-8.

24. Jabin M, Fouzia Gul F. Abruptio Placentae: Risk Factors and Perinatal Outcome. JPMI. 1995; 18(4):66976.

25. Bibi S, Ghaffar S, Pir AM, Yousfani S. Risk factors and clinical outcome of placental abruption: a retrospective analysis. J Pakistan Medical Associat. 2009;59(10):672.

Cite this article as: Chavan NN, Rohidas V, Waikule H. Accidental haemorrhage in third trimester: maternal and fetal outcome. Int J Reprod Contracept Obstet Gynecol 2019;8:1633-6. 